\title{
Intelligent $\mathrm{CO}_{2}$ Monitoring for Diagnosis of Sleep Apnea Using Neural Cryptography Techniques
}

\author{
Manar Ahmed Hamza ${ }^{D},{ }^{1}$ Maha M. Althobaiti, ${ }^{2}$ Ola Abdelgney Omer Ali, ${ }^{3}$ \\ Souad Larabi-Marie-Sainte, ${ }^{4}$ Majdy M. Eltahir, ${ }^{5}$ Anwer Mustafa Hilal, ${ }^{1}$ \\ Mesfer Al Duhayyim, ${ }^{6}$ and Ishfaq Yaseen ${ }^{1}$ \\ ${ }^{1}$ Department of Computer and Self Development, Preparatory Year Deanship, Prince Sattam Bin Abdulaziz University, \\ Al-Kharj, Saudi Arabia \\ ${ }^{2}$ Department of Computer Science, College of Computing and Information Technology, Taif University, P.O. Box 11099, \\ Taif 21944, Saudi Arabia \\ ${ }^{3}$ Department of Information Technology, College of Computer, Qassim University, Buraydah, Saudi Arabia \\ ${ }^{4}$ Department of Computer Science, College of Computer and Information Sciences, Prince Sultan University, Saudi Arabia \\ ${ }^{5}$ Department of Information Systems, College of Science \& Art at Mahayil, King Khalid University, Saudi Arabia \\ ${ }^{6}$ Department of Natural and Applied Sciences, College of Community-Aflaj, Prince Sattam Bin Abdulaziz University, Saudi Arabia
}

Correspondence should be addressed to Manar Ahmed Hamza; ma.hamza@psau.edu.sa

Received 8 November 2021; Revised 12 December 2021; Accepted 18 December 2021; Published 18 January 2022

Academic Editor: Jeevan Kumar Reddy Modigunta

Copyright (C) 2022 Manar Ahmed Hamza et al. This is an open access article distributed under the Creative Commons Attribution License, which permits unrestricted use, distribution, and reproduction in any medium, provided the original work is properly cited.

\begin{abstract}
In biomass wastage, carbon is one of the adsorbent materials. Biomass wastage contains complex materials, and pressure, various temperatures, and presence of various chemical components which are subjected to the adsorption of carbon are a tedious task, and it is used in the sustainable waste management system. While screening the biomass wastage management system, prediction of activated carbon's quality and understanding of the mechanism of adsorption of $\mathrm{CO}_{2}$ are a complicated task. Many research works have been developed; the main issues are inaccurate and inefficient prediction of carbon available in the various feedstock of biomass wastage. To overcome these issues, this paper proposed gene expression programming (GEP) with $K$ -nearest neighbour (GEP-KNN). The key advantage of the proposed work shows excellent performance in the prediction of adsorbing carbon and accuracy. The accuracy of the GEP-KNN algorithm with different $K$ values produced the highest accuracy at $K=9$ and $k=10$ of $95.12 \%$ and $95.67 \%$; the lowest accuracy is $K=1$ of $65.34 \%$.
\end{abstract}

\section{Introduction}

In the ecosystem of the globe, one of the main sources is storage of carbon in the terrestrial ecosystem which creates terrestrial biomass [1]. The huge amount of carbon availability in the ecosystem plays a vital role in reducing global warming $[2,3]$. Adsorption of carbon in biomass wastage has been taken as a vital role for reducing $\mathrm{CO}_{2}$ emission [4-7]. Activated carbon is an adsorbent component of biomass wastage with large adsorption capacity, superior surface reactivity, and high porosity. It can be used in the field of water treatment, agricultural wastage water treatment, industrial application, and pharmaceutical [8-10]. The toxic pollutants available in the terrestrial, industrial wastage water, and drinking water are important environmental issues. Adsorption has become one of the best techniques in removing pollutants. Activated carbon acts as an adsorbent material for purifying the water and reduces the pollutant content.

For implementing the concept of adsorption of carbon in the biomass wastage system, so much research works have been done. The major drawbacks are poor quality, ineffectiveness, high time consumption, and inaccuracy. To 
overcome these drawbacks, the proposed work GEP-KNN predicts the adsorption of $\mathrm{CO}_{2}$ in the biomass wastage system. This proposed work provides the best technique in the aspects of providing highly accurate detection of $\mathrm{CO}_{2}$ in an effective way. Time consumption is also low and minimizes the error rate. This proposed work fills gaps of existing research work by impacting the interaction of biomass wastage system and implementing the properties of activated carbon using GEP-KNN.

Machine learning approaches include support vector regression, linear regression, and random forest regression for the prediction of iodine component in the activated carbon product. This technique includes various types of straw like carbonization and activation methods [11]. Implementing geometric expression programming includes Symbiotic Gene Expression Programming (SGEP) which is based on the concept of symbiotic algorithm which improves the process, and it has low-efficiency issues when it handles a complex problem [12]. This paper [13] computationally proposed GEP in terms of the expression tree. Therefore, it can reduce the chromosomes. The main contribution of this work includes

(1) improving efficiency; we proposed GEP with KNN. This classifier provides high-quality prediction of $\mathrm{CO}_{2}$ in the biomass wastage system

(2) implementing texture properties in biomass wastage and performing the evaluation in the metric measures of the correlation coefficient, RMSE, and bias

The paper has been organized as follows: Section 2 describes the review of the literature, Section 3 introduces prediction of $\mathrm{CO}_{2}$ in the biomass wastage system using GEP with KNN, Section 4 discusses the experimented results, and Section 5 concludes the paper with future directions.

\section{Review of Literature}

Due to the development of industrialization and increase in population, the environment got polluted and there is increased global warming. To reduce global warming in the polluted environment, adsorption of carbon from biomass wastage is needed to protect our globe from global warming. The form of activated carbon is in a microporous form of carbon with the structure of volume, surface area, and capacity of high adsorption [14]. For reducing the emission of $\mathrm{CO}_{2}$, adsorption is needed in the aspects of cryogenic, adsorption, membrane, and microalgal biofixation. It separates $\mathrm{CO}_{2}$ and reduces the regeneration energy requirements [15]. Adsorption of isotherms of $\mathrm{CO}_{2}$ is available and also at various pressures and temperatures by using the volumetric process [16]. This paper [17] proposed that activated carbon is taken as a precursor and provided into disposal of sustainable wastage. And it associates developing the environment which increases concerns; there is an increased research interest to find low-cost biomass waste materials as well as low-cost processes for production.

The development of civilization and agriculture and at the same time wastage from industry and agriculture are considered precursors of activated carbon production [18]. Similarly, open burning of wastage emits obnoxious gases and particulate matter which pollute the environment, and also, during the rainy season, deposition of wastage will block drainage channels. These deposited wastages are considered biomass wastage and exhibit activated carbon for adsorption $[19,20]$. Tables 1 and 2 shows survey on adsorption of $\mathrm{CO}_{2}$ in biomass.

\section{Proposed Methodology}

$\mathrm{CO}_{2}$ adsorption in the biomass waste management system is at various temperatures and pressure with various thermodynamic properties like isosteric heat of adsorption, entropy, and Gibbs free energy. In this proposed work, we implement the fusion of GEP with KNN algorithm to improve the efficiency and accurate prediction of $\mathrm{CO}_{2}$. The architecture of the proposed work (GEP with KNN) is given in Figure 1.

Figure 1 describes three phases, namely, data collection, preprocessing, and analysis of GEP-KNN.

\subsection{Preprocessing}

3.1.1. Normalization. To enhance the quality of the GEPKNN algorithm's output, it undergoes data normalization by using the function of linear normalization as given below:

$$
\operatorname{Norm}_{i, j}=\frac{\operatorname{data}_{i, j}-\operatorname{Min}_{j}}{\operatorname{Max}_{j}-\operatorname{Min}_{j}}
$$

where $\operatorname{Norm}_{i, j}$ is the value normalized for the data sample point data ${ }_{i, j}$ and $\operatorname{Max}_{j}, \operatorname{Min}_{j}$ are parameter values of minimum and maximum.

\subsection{Applying Proposed Method of GEP-KNN}

3.2.1. Overview of GEP. Gene expression programming (GEP) is an evolutionary-based computation algorithm. This algorithm is based on the inheritance concept of genotype from the genetic algorithm (GA) and phenotype from genetic programming (GP). The prediction of $\mathrm{CO}_{2}$ in biomass GEP plays a vital role in the aspect of handling multiple components available in biomass wastage, and also, it is faster than genetic programming (GP). Genotype acts like GA, and phenotype is like a tree structure format with variable size and length. Based on the threshold values of phenotype and replicator, it produced the output. It implements the relationship between various components available in biomass wastage by applying the Boolean logical operators like AND, OR, and NOT with the algebraic operators of + , ,$- \times, \div$.

3.2.2. GEP in Biomass Wastage. Finding the relationship of components in biomass wastage with respect to the variables used in the GEP algorithm is creating a population of linear chromosomes. For each component in the biomass waste, the position of $\mathrm{CO}_{2}$ genes of these chromosomes and its variable is placed. Once $\mathrm{CO}_{2}$ is identified and its position is filled, evaluate the fitness of each $\mathrm{CO}_{2}$ component (chromosome) in biomass wastage. In the GEP algorithm, all 
TABLE 1: Adsorption of $\mathrm{CO}_{2}$ in biomass.

\begin{tabular}{|c|c|c|c|}
\hline Author & Aim & Adsorbent & Pollutant \\
\hline Delgado-Moreno et al. [21] & $\begin{array}{l}\text { New insights into the efficient removal } \\
\text { of emerging contaminants by biochars and } \\
\text { hydrochars derived from olive oil wastes }\end{array}$ & Biomass & Biochars and hydrochars \\
\hline Egirani et al. [22] & $\begin{array}{l}\text { Powdered and granular activated carbon } \\
\text { from Palmae biomass for mercury removal }\end{array}$ & Biomass & Mercury removal \\
\hline Govindan et al. [23] & $\begin{array}{c}\text { Activated carbon derived from Phoenix dactylifera } \\
\text { (palm tree) and decorated with } \mathrm{MnO}_{2} \text { nanoparticles } \\
\text { for enhanced hybrid capacitive deionization } \\
\text { electrodes }\end{array}$ & Biomass & $\begin{array}{l}\text { Dactylifera with } \mathrm{MnO}_{2} \\
\text { nanoparticles }\end{array}$ \\
\hline Khorasgani et al. [24] & $\begin{array}{l}\text { Briquetting grass and tree leaf biomass for } \\
\text { sustainable production of future fuels }\end{array}$ & Biomass & Briquetting grass and tree leaf \\
\hline Anastopolous et al. [25] & $\begin{array}{l}\text { Agricultural biomasses for the removal of toxic } \\
\text { metal(oid)s from contaminated aqueous solutions }\end{array}$ & Biomass & Toxic metal(oid)s \\
\hline Wei et al. [26] & $\begin{array}{l}\text { Petrochemical wastewater and produced water } \\
\text { from oil and gas production are reviewed }\end{array}$ & $\begin{array}{l}\text { Chitosan-activated } \\
\text { montmorillonite, } \\
\text { nutshell filters, etc. }\end{array}$ & $\begin{array}{l}\text { Petrochemical wastewater } \\
\text { and produced water from oil } \\
\text { and gas }\end{array}$ \\
\hline Doshi et al. [27] & $\begin{array}{l}\text { Recovery of spilled oils using biomass } \\
\text { and polymers, as sorbents or separators }\end{array}$ & Biomass & $\begin{array}{l}\text { Diesel, crude oil, gasoline, } \\
\text { waste lubricating oil, etc. }\end{array}$ \\
\hline Wong et al. [28] & $\begin{array}{l}\text { The use of ACs prepared from magnetic materials } \\
\text { and nanoparticles in wastewater purification } \\
\text { compared to biochars derived from biowaste }\end{array}$ & Biomass & Dyes, heavy metals \\
\hline
\end{tabular}

TABLE 2: The parameters which are used in GEP model.

\begin{tabular}{lcc}
\hline Parameter & Parametric function name & Parametric value \\
\hline$P_{1}$ & Function set & $+,-, \times, /, \sqrt{ }, e^{x}, \ln (x)$, etc. \\
$P_{2}$ & Chromosome's value & $20-50$ \\
$P_{3}$ & Size of head & $5,7,9$ \\
$P_{4}$ & Number of genes & 4 \\
$P_{5}$ & Function for linking & Addition, multiplication \\
$P_{6}$ & Function for fitness in error type & 0.055 \\
$P_{7}$ & Rate of mutation & 0.1 \\
$P_{8}$ & Rate of inversion & 0.4 \\
$P_{9}$ & Recombination rate of one point & 0.4 \\
$P_{10}$ & Recombination rate of two points & 0.2 \\
$P_{11}$ & Recombination rate of gene & 0.2 \\
$P_{12}$ & Transposition rate of gene & 0.2 \\
\hline
\end{tabular}

identification of $\mathrm{CO}_{2}$ component (chromosome) is represented by expression tree (ET) format. That is similar to gene's phenotype [29]. Then, select the next component as the next generation; construct the linear genotype state of the chromosome as applied.

The most important parameters used in the GEP algorithm is creating expression trees (ET) and chromosomes. The process of transforming information (chromosomes) to ET is based on a set of rules, and it is known as translation. Evaluate the genetic code by one-to-one relationship between chromosome symbols with terminal values or functions. The GEP algorithmic steps are given in Algorithm 1.
Algorithm 1 seems to evaluate the fitness function and choose the functions and terminals. Construct the structure of chromosomes based on the gene number and length and number of generations. Apply linking function and train the model of GEP until current generation is evaluated and repeat the process for executing the next generation.

3.2.3. KNN. The $K$-nearest neighbour algorithm is one of the most popular classification algorithms. The KNN algorithm is selecting the new component of the unknown category for the classification. The KNN classification algorithm can be 


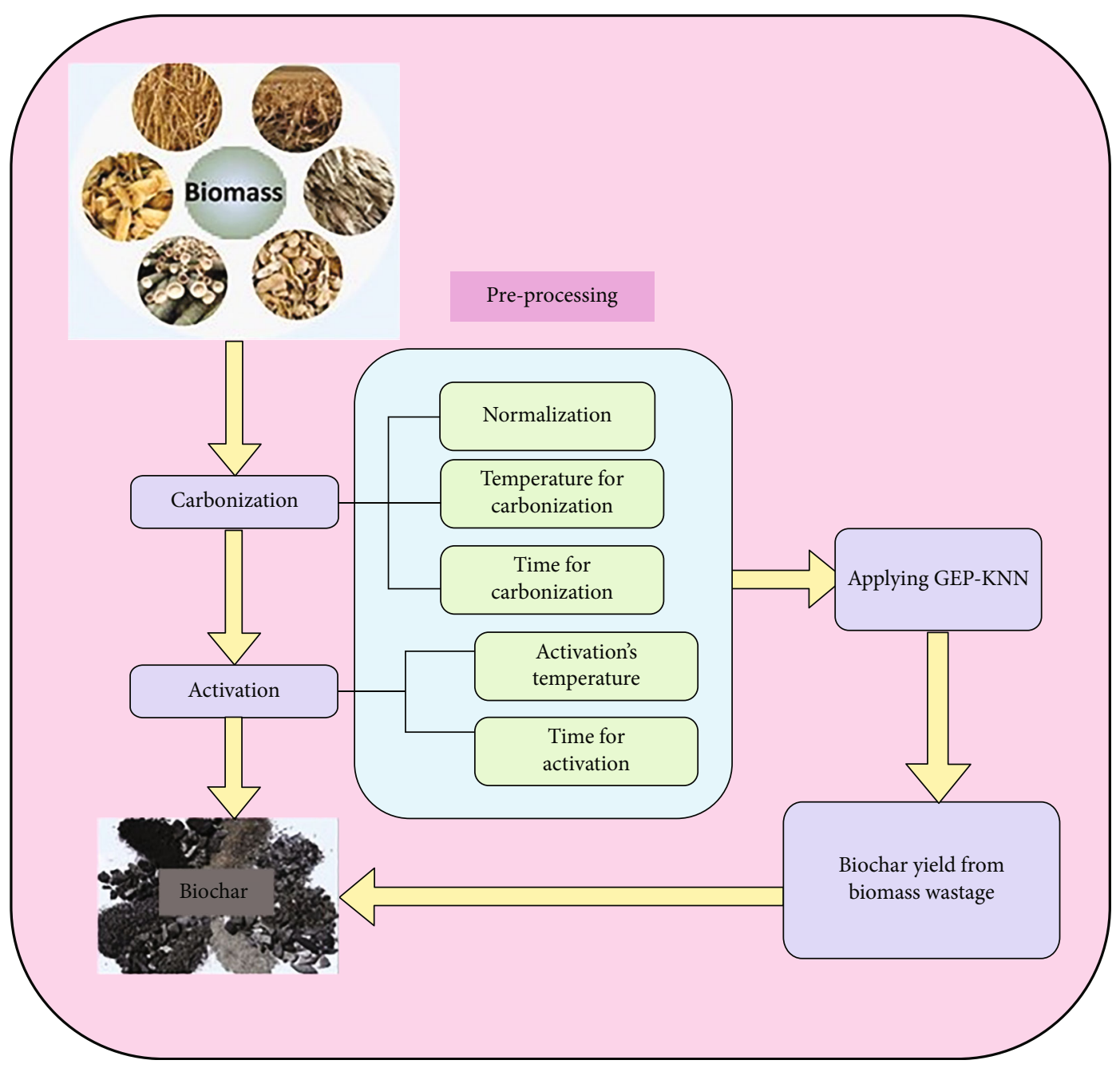

FIGURE 1: Architecture of proposed work.

Step 1. Initialize the population.

Step 2. Execute chromosome expression as ET.

Step 3. Calculate fitness function by using

fit $_{i}=\sum_{j=1}^{c_{i}}\left(M-\left|\operatorname{Chr}_{(i, j)}-\operatorname{Targ}_{j}\right|\right)$ where $M$ is the selection range value and $\mathrm{Chr}_{(i, j)}$ is the fitness value of individual chromosome and $\operatorname{Targ}_{j}$ is the target value of fitness value for $j .\left|\mathrm{Chr}_{(i, j)}-\operatorname{Targ}_{j}\right|$ is the precision.

Step 4. If $\left|\mathrm{Chr}_{(i, j)}-\operatorname{Targ}_{j}\right| \leq 0.01$, then the precision value is 0 .

Step 5. fit $_{i}=$ fit $_{\max }=\mathrm{Chr}_{i} M$; here, consider $M=100$, and now, $\mathrm{fit}_{\max }=1000$.

Step 6. Create chromosomes by selecting the set of terminals and function by using parametric value $P_{1}$.

Step 7. Select the architecture of chromosomes in the aspects of head length and number of genes in the chromosome.

Step 8. Use the parametric value of $P_{5}$ linking all subexpression functions of tree value by using addition operation. There are three types of transportation and three types of recombination.

Step 9. Use all operators of genetic, namely, mutation, three types of transportation, and three types of recombination as in the parametric table.

Step 10. To create a new chromosome, go to Step 2. Repeat it until all chromosomes get evaluated.

Algorithm 1: GEP for biomass wastage.

used to compute both regression and classification. Selecting the sample training $P=\left\{x_{1}, x_{2}, \cdots, x_{n}\right\}$, and sampling data is distributed in $A$ and categorized into $D_{1}, D_{2}, \cdots, D_{n}$. From the training data set of values, evaluate the nearest sample value using discriminant function $F_{i}$. Identify $K$ of the neighbour samples with $F_{i}(x)=K_{i}$, where $i=1,2,3, \cdots, N$. Select the sample of data and evaluate $y_{i}(x)=\operatorname{Max}\left(K_{i}\right)$. The algorithm for KNN is given in Algorithm 2. 
Step 1. Split the data set into the training and testing data sets and consider training sample data set $P=\left\{x_{1}, x_{2}, \cdots, x_{n}\right\}$. And the category of sample $D=D_{1}, D_{2}, \cdots, D_{n}$. And testing sample data $S=\left\{S_{1}, S_{2}, \cdots, S_{N}\right\}$.

Step 2. Take the initial $k$ value and choose the initial nearest neighbour to $X$.

Step 3. Evaluate the distance between the test data set and all other training data set values.

Step 4. Sort the output distance values in ascending order and select the appropriate $k$ value.

Step 5. Choose the closest $k$ known sample values.

Step 6. Count the sample of categories with the highest probability within the $k$ known sample values.

Step 7. Implement the category of test sample data value as the category obtained by statistics using Step 6.

Algorithm 2: KNN algorithm.

Step 1. For each instance value in the training data set tins $s_{i} \in T / / T$ is the training data set.

Step 2. Encode component (chromosome) $\mathrm{chr}_{j}$ of biomass wastage in tins $s_{i}$.

Step 3. For each instance value tins ${ }_{i}$ in $T$

Step 4. Read tins $s_{i}$ and $\mathrm{chr}_{j}$ into GEP

Step 5. Consider $\mathrm{chr}_{j}$ as $y$ and tins ${ }_{i}$ as $x$.

Step 6. Initiate the basic component functions of GEP: function set, link function, mutation selection, crossover, and fitness using Equation (3).

Step 7. For each generation, GEP implement Algorithm 1 (Step 3 to Step 5)

Step 8. Until termination condition or fitness criteria satisfied.

Step 9. Output of GEP represents $\mathrm{chr}_{j}=f\left(\right.$ tins $\left._{i}\right)$

Step 10. Initialize $\mathrm{KNN}(\mathrm{GEP}) / /$ using Algorithm 2

Step 11. Consider $\sigma$ as threshold value

Step 10. For each $\mathrm{chr}_{j}$ in training data set do

Step 11. Evaluate $y_{e}=f\left(\right.$ tins $\left._{e i}\right)$

Step 12. If $\left|y_{e}-\operatorname{chr}_{j}\right| \leq \sigma$

Step 13. $\operatorname{tins}_{e i} \in \operatorname{chr}_{j}(2)$

Step 14. Else tins ${ }_{e i} \longleftarrow$ KNN.classify $\left(\mathrm{chr}_{j}\right)$

Step 15. End if

Step 16. End for

Step 17. End for

Step 18. tins $_{e i} \longleftarrow$ evaluate the prediction list

Step 19. End

Algorithm 3: Adsorption of carbon GEP-KNN (proposed).

TABLE 3: Evaluation of metric measures.

\begin{tabular}{|c|c|c|c|c|c|c|}
\hline & \multicolumn{3}{|c|}{ Train } & \multicolumn{3}{|c|}{ Test } \\
\hline & GA [32] & GEP & GEP-KNN & GA & GEP & GEP-KNN \\
\hline Correlation coefficient & 0.8911 & 0.9443 & 0.9751 & 0.8911 & 0.9643 & 0.9951 \\
\hline Root mean square & 7.4562 & 6.4185 & 5.3452 & 12.4551 & 16.6792 & 11.3452 \\
\hline Mean relative error & 6.4597 & 4.6575 & 3.893 & 13.4563 & 6.5789 & 4.3678 \\
\hline Bias & -0.4522 & -1.5482 & -1.3793 & -4.5824 & 3.4566 & 2.4367 \\
\hline
\end{tabular}

The KNN algorithm describes the classification of the unknown component from extracting the features of it and compared it with the sample category of data. Choose the $K$-nearest neighbour and count the data which belongs to the same category of data.

3.2.4. Fusion of GEP-KNN Proposed Technology. In order to get high quality in an effective way of absorption of carbon in the biomass wastage system, this proposed work is implemented. The procedure for GEP-KNN is given in Algorithm 3.
Algorithm 3 describes fusion of GEP with the KNN algorithm. In the execution of GEP, it predicts the $\mathrm{CO}_{2}$ component from biomass wastage. The training data set for each component undergoes Algorithm 1 and produces the output as adsorption of carbon and then applied to the KNN algorithm for getting more accurate and effective classification. Because the KNN algorithm is a supervised classification algorithm, it checks each component in the output set and chooses its neighbour value to evaluate the exact component. 

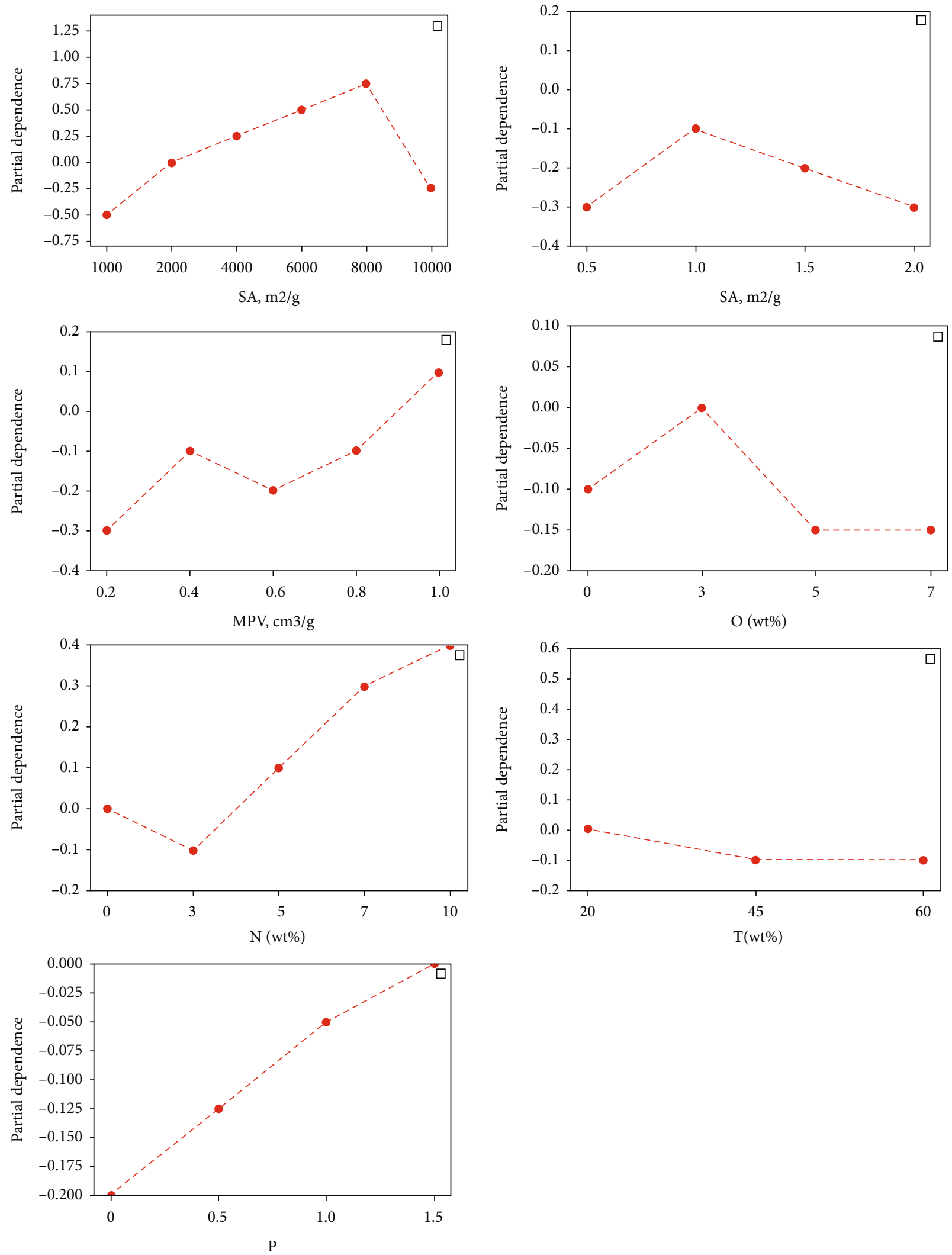

FIGURE 2: Input features of adsorption of $\mathrm{CO}_{2}$ in biomass wastage. 


\section{Result and Analysis}

4.1. Data Collection. Data is collected from peer-viewed journals using different keywords like biomass, biochar, and $\mathrm{CO}_{2}$ adsorption, and 632 data points were collected and used in this work [30]. Most of the data were collected from the researcher's report by using WebPlotDigitizer software [31]. The GEP model was implemented by using GeneXproTools 5.0. From the total data points, we randomly selected $80 \%$ of data points and labelled them as the training data set and the remaining $20 \%$ of data points are selected and labelled as the testing data set. The features of collected input data are divided into three categories, namely, properties of texture data, elementary composition of biomass wastage, and $\mathrm{CO}_{2}$ adsorption parameters such as temperature and pressure. The texture properties of biomass wastage are total pore volume (TPV, $\left.\mathrm{cm}^{3} / \mathrm{g}\right)$, surface area $\left(\mathrm{SA}, \mathrm{m}^{2} / \mathrm{g}\right)$, and micropore volume $\left(\mathrm{MPV}, \mathrm{cm}^{3} / \mathrm{g}\right)$. The basic elemental compositions are carbon, oxygen, hydrogen, and nitrogen contents (wt\%). These machine learning algorithms implemented as used here were performed in Python using the open-source scikit-learn library.

4.2. Performance of Metric Measures. The performance is evaluated in terms of correlation coefficient $\left(R^{2}\right)$ and root mean square error (RMSE) as defined below:

$$
\begin{aligned}
R^{2} & =1-\frac{\sum_{n=1}^{N}(y \wedge-y)^{2}}{\sum_{n=1}^{N}(y \wedge-\bar{y})^{2}}, \\
\operatorname{RMSE} & =\sqrt{\frac{\sum_{n=1}^{N}(y \wedge-y)^{2}}{N},} \\
\operatorname{MRE} & =\frac{\left(\widehat{y}_{l}-y_{i}\right)}{y_{i}} \times 100, \\
\operatorname{Bias}(\%) & =100 \times \frac{1}{n} \times \sum_{i=1}^{n}\left[\frac{\left(\widehat{y}_{l}-y_{i}\right)}{y_{i}}\right],
\end{aligned}
$$

where $\hat{y}, y$, and $\bar{y}$ are predicted, actual, and mean values of the targeted component, and $n$ is the number of data points for any instance, and $N$ is the total number of data points. In this work GEP-KNN, the metric measures of its performance based on accuracy, specificity, sensitivity, precision, and $F$-score evaluation matrices were employed:

$$
\begin{aligned}
\text { accuracy } & =\frac{\mathrm{TP}+\mathrm{TN}}{\mathrm{TP}+\mathrm{TN}+\mathrm{FP}+\mathrm{FN}}, \\
\text { precision } & =\frac{\mathrm{TP}}{\mathrm{TP}+\mathrm{FP}}, \\
\text { recall } & =\frac{\mathrm{TP}}{\mathrm{TP}+\mathrm{FN}}, \\
F 1-\text { Score } & =\frac{2 * \text { precision } * \text { recall }}{\text { precision }+ \text { recall }} .
\end{aligned}
$$

Table 3 shows evaluation of metric measures.
TABle 4: Metric measure report.

\begin{tabular}{lccc}
\hline Parameter & GA & GEP & GEP-KNN \\
\hline TP & 142 & 160 & 130 \\
TN & 113 & 128 & 50 \\
FP & 75 & 45 & 25 \\
FN & 80 & 50 & 20 \\
Accuracy & 0.79 & 0.90 & 0.98 \\
Precision & 0.72 & 0.91 & 0.95 \\
Recall & 0.71 & 0.94 & 0.97 \\
\hline
\end{tabular}

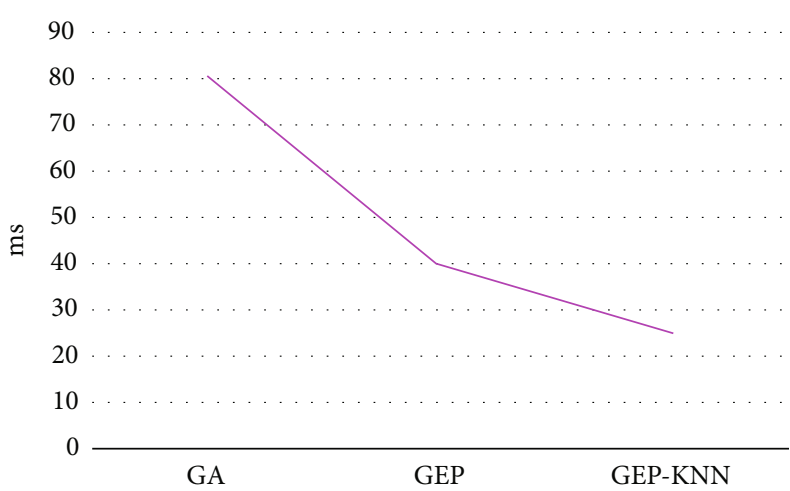

Figure 3: Computation time.

Table 3 shows that the performance of evaluation based on correlation coefficient, RMSE, MRE, and bias implemented in genetic algorithm (GA), GEP, our proposed work (GEP-KNN) algorithms in both training and testing data sets. The correlation coefficient shows strongly correlated 0.94 in the training phase and 0.96 in the testing phase. RMSE shows below $8 \%$ in the training phase and in the testing phase below $17 \%$. For the bias value, it is underestimated in the training phase whereas in the testing phase, GEP and GEP-KNN algorithms are overestimated compared with GA. For the mean relative error, in the training phase, there is a little bit of increase when compared with the testing phase for each algorithm. That is, GA error is increased in the testing phase and so on. Figure 2 shows adsorption of $\mathrm{CO}_{2}$ in biomass wastage input features like SA, MPV, $\mathrm{TPV}$, oxygen $(\mathrm{O})$, temperature $(\mathrm{T})$, and pressure $(\mathrm{P})$.

Figure 2 shows the impact of input features of $\mathrm{CO}_{2}$ adsorption in biomass wastage. The input features like surface area $\left(\mathrm{SA}, \mathrm{m}^{2} / \mathrm{g}\right)$ reach $8000 \mathrm{~m}^{2} / \mathrm{g}$. Total pore volume (TPV, $\mathrm{cm}^{3} / \mathrm{g}$ ) got the maximum reach at $-0.1 \mathrm{~cm}^{3} / \mathrm{g}$. Micropore volume $\left(\mathrm{MPV}, \mathrm{cm}^{3} / \mathrm{g}\right)$ reaches $1 \mathrm{~cm}^{3} / \mathrm{g}$. Table 4 shows the report of performance metric measures.

From Table 4, the accuracy of GEP-KNN (proposed work) is higher as compared to other classifier algorithms of GA and GEP. In Table 4, the next higher accuracy is GEP which is also closer to GEP-KNN. Figure 3 shows the computation time for $\mathrm{CO}_{2}$ adsorption in various algorithms like GA GEP and GEP-KNN.

Figure 3 shows that the proposed work needs less computation time for the prediction of $\mathrm{CO}_{2}$ adsorption in 


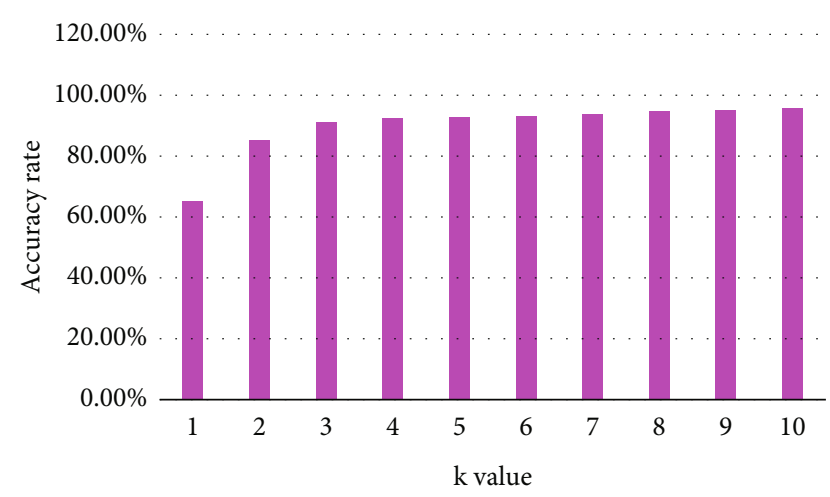

FIgURE 4: Accuracy rate for various $K$-values.

TABle 5: Effectiveness.

\begin{tabular}{lcc}
\hline Algorithms & TN & TP \\
\hline GA & 65 & 55 \\
GEP & 45 & 34 \\
GEP-KNN & 92 & 82 \\
\hline
\end{tabular}

biomass wastage. Figure 4 shows the accuracy rate for implementation GEP-KNN with various $K$ values.

Figure 4 shows that the value of $K$ having the highest accuracy is $K=9$ and $k=10$ with the rate of accuracy as $95.12 \%$ and $95.67 \%$; the lowest accuracy is $K=1$ of $65.34 \%$. Table 5 shows the effectiveness of various machine learning algorithms in terms of various influent indicators by using

$$
\text { Effectiveness }=\frac{N-L}{N} \times 100 \text {, }
$$

where $N$ is the total number of testing data and $L$ is the total number of losing test data.

Table 5 shows that the effectiveness of our proposed work produces better results compared with other existing algorithms.

\section{Conclusion}

The adsorption of $\mathrm{CO}_{2}$ in biomass wastage uses evolutionary algorithms of gene expression programming (GEP) with $K$ -nearest neighbour (KNN). This algorithm is implemented in the aspect of texture properties of biomass wastage like total pore volume $\left(\mathrm{TPV}, \mathrm{cm}^{3} / \mathrm{g}\right)$, surface area $\left(\mathrm{SA}, \mathrm{m}^{2} / \mathrm{g}\right)$, and micropore volume (MPV, $\left.\mathrm{cm}^{3} / \mathrm{g}\right)$. Based on these texture properties, our proposed work (GEP-KNN) effectively predicts the adsorption of $\mathrm{CO}_{2}$ in biomass wastage at a minimum error rate value and low computation time. The accuracy of the GEP-KNN algorithm with different $K$ values produced the highest accuracy at $K=9$ and $k=10$ of $95.12 \%$ and $95.67 \%$; the lowest accuracy is $K=1$ of $65.34 \%$. Our proposed work GEP-KNN outperforms the best result compared with existing classifiers. In future work, this will be extended by using various ML algorithms, and also, we will upgrade our work in various texture properties for predicting various components in biomass wastage.

\section{Data Availability}

All the required data is available in the manuscript itself.

\section{Conflicts of Interest}

The authors declare that they have no conflicts of interest.

\section{Acknowledgments}

The authors extend their appreciation to the Deanship of Scientific Research at King Khalid University for funding this work under grant number RGP.1/172/42. We deeply acknowledge Taif University for supporting this research through the Taif University Researchers Supporting Project Number (TURSP-2020/328), Taif University, Taif, Saudi Arabia. The authors would like to acknowledge the support of Prince Sultan University, Riyadh, Saudi Arabia, for partially supporting this project by paying the Article Processing Charges (APC) of this publication.

\section{References}

[1] F. S. Chapin, P. A. Matson, and H. A. Mooney, Principles ofTerrestrial Ecosystem Ecology, Springer, New York, NY, USA, 2002.

[2] R. A. Houghton, "Aboveground forest biomass and the Global Carbon balance," Global Change Biology, vol. 11, no. 6, pp. 945-958, 2005.

[3] P. Vicharnakorn, R. Shrestha, M. Nagai, A. Salam, and S. Kiratiprayoon, "Carbon stock assessment using remotesensing and forest inventory data in Savannakhet, Lao PDR," Remote Sensing, vol. 6, no. 6, pp. 5452-5479, 2014.

[4] A. E. Creamer and B. Gao, "Carbon-based adsorbents for postcombustion CO2Capture: a critical review," Environmental Science \& Technology, vol. 50, no. 14, pp. 7276-7289, 2016.

[5] M. Yang, L. Guo, G. Hu et al., "Highly cost-effective nitrogendoped porous coconut shell-based CO2Sorbent synthesized by combining ammoxidation with $\mathrm{KOH}$ activation," Environmental Science \& Technology, vol. 49, no. 11, pp. 7063-7070, 2015.

[6] J. Wang, X. Yuan, S. Deng et al., "Waste polyethylene terephthalate (PET) plastics-derived activated carbon for CO2capture: a route to a closed carbon loop," Green Chemistry, vol. 22, no. 20, pp. 6836-6845, 2020.

[7] P. D. Dissanayake, S. W. Choi, A. D. Igalavithana et al., "Sustainable gasification biochar as a high efficiency adsorbent for $\mathrm{CO}_{2}$ capture: a facile method to designer biochar fabrication," Renewable and Sustainable Energy Reviews, vol. 124, article 109785, 2020.

[8] A. Mohammad-Khah and R. Ansari, "Activated charcoal:preparation, characterization and applications: A reviewarticle," International Journal of ChemTech Research, vol. 1, no. 4, pp. 859-864, 2009.

[9] J. M. Dias, M. C. M. Alvim-Ferraz, M. F. Almeida, and M. Rivera-Utrilla Jand Sánchez-Polo, "Waste materials for activated carbon preparation and its use in aqueous-phase 
treatment: A review," Journal of Environmental Management, vol. 85, no. 4, pp. 833-846, 2007.

[10] X. Tan, S. Liu, Y. Liu et al., "Biochar as potential sustainable precursors for activated carbon production: Multiple applications in environmental protection and energy storage," Bioresource Technology, vol. 227, pp. 359-372, 2017.

[11] W. Jiang, X. Xing, S. Li, X. Zhang, and W. Wang, "Synthesis, characterizationand machine learning based performance predictionof straw activated carbon," Journal of Cleaner Production, vol. 212, pp. 1210-1223, 2019.

[12] S. Xue and J. Wu, "Gene expression programming based onsymbiotic evolutionary algorithm," in Proceedings of the 2nd International Conference on Artificial Intelligence, ManagementScience and Electronic Commerce (AIMSEC '11), pp. 3055-3058, India, 2011.

[13] Y. Chen, C. J. Tang, R. Li, M. F. Zhu, C. Li, and J. Zuo, "Reduced-GEP: improving gene expression programming by gene reduction," in Proceedings of the 2nd International Conference onIntelligent Human-Machine Systems and Cybernetics (IHMSC'10), pp. 176-179, Nanjing, China, 2010.

[14] R. B. Galvão, A. A. da Silva Moretti, F. Fernandes, and E. K. Kuroda, "Post-treatment of stabilized landfill leachate by upflow gravel filtration and granular activated carbon adsorption," Environmental Technology, vol. 42, no. 26, pp. 41794188, 2020.

[15] V. K. Singh and E. Anil Kumar, "Measurement and analysis of adsorption isotherms of $\mathrm{CO}_{2}$ on activated carbon," Applied Thermal Engineering, vol. 97, pp. 77-86, 2016.

[16] A. I. Osamn, M. Hefny, M. I. A. Abdel Maksoud, A. M. Elgarahy, and D. W. Rooney, "Recent advances in carbon capture storage and utilisation technologies: a review," Environmental Chemistry Letters, vol. 19, no. 2, pp. 797-849, 2021.

[17] J. Wang, L. Huang, R. Yang et al., "Recent advances in solid sorbentsfor $\mathrm{CO}_{2}$ capture and new development," Trends, Energy \& Environmental Science, vol. 7, pp. 3478-3518, 2014.

[18] K. N. Palansooriya, Y. Yang, Y. F. Tsang et al., "Occurrence of contaminants in drinking water sources and the potential of biochar for water quality improvement: a review," Critical Reviews in Environmental Science and Technology, vol. 50, no. 6, pp. 549-611, 2020.

[19] H. N. Tran, H. C. Nguyen, S. H. Woo et al., "Removal of various contaminants from water by renewable lignocellulosederived biosorbents: a comprehensive and critical review," Critical Reviews in Environmental Science and Technology, vol. 49, pp. 2155-2219, 2019.

[20] E. Santoso, R. Ediati, Y. Kusumawati, H. Bahruji, D. O. Sulistiono, and D. Prasetyoko, "Review on recent advances of carbon based adsorbent for methylene blue removal from waste water," Materials Today Chemistry, vol. 16, article 100233, 2020.

[21] L. Delgado-Moreno, S. Bazhari, G. Gasco, A. Mendez, M. El Azzouzi, and E. Romero, "New insights into the efficient removal ofemerging contaminants by biochars and hydrochars derived from olive oil wastes," Science of The Total Environment, vol. 752, article 141838, 2021.

[22] D. Egirani, M. T. Latif, N. Wessey, N. R. Poyi, and N. Shehata, "Preparation and characterization of powdered and granular activated carbon from Palmae biomass for mercury removal," Applied Water Science, vol. 11, no. 1, 2021.

[23] B. Govindan, E. Alhseinat, I. F. F. Darawsheh et al., "Activated Carbon derived fromPhoenix dactylifera(Palm tree) and deco- rated with $\mathrm{MnO} 2 \mathrm{Nanoparticles} \mathrm{for} \mathrm{enhanced} \mathrm{hybrid} \mathrm{Capaci-}$ tive Deionization electrodes," ChemistrySelect, vol. 5, no. 11, pp. 3248-3256, 2020.

[24] N. B. Khorasgani, A. B. Sengul, and E. Asmatulu, "Briquetting grass and tree leaf biomass for sustainable production of future fuels," Biomass Conversion and Biorefinery, vol. 10, pp. 915924, 2020.

[25] I. Anastopoulos, I. Pashalidis, A. Hosseini-Bandegharaei et al., "Agricultural biomass/waste as adsorbents for toxic metal decontamination of aqueous solutions," Journal of Molecular Liquids, vol. 295, article 111684, 2019.

[26] X. Wei, S. Zhang, Y. Han, and F. A. Wolfe, "Treatment of petrochemical wastewater and produced water from oil and gas," Water Environment Research, vol. 91, no. 10, pp. 1025-1033, 2019.

[27] B. Doshi, M. Sillanpaa, and S. Kalliola, "A review of bio-based materialsfor oil spill treatment," Water Research, vol. 135, pp. 262-277, 2018.

[28] S. Wong, N. Ngadi, I. M. Inuwa, and O. Hassan, "Recent advances inapplications of activated carbon from biowaste for wastewatertreatment: a short review," Journal of Cleaner Production, vol. 175, pp. 361-375, 2018.

[29] A. Guven and M. Gunal, "Genetic programming approach for prediction of Local Scour downstream of hydraulic structures," Journal of Irrigation and Drainage Engineering, vol. 134, no. 2, pp. 241-249, 2008.

[30] X. Yuan, M. Suvarna, S. Low et al., “Applied machine learning for prediction of $\mathrm{CO}_{2}$ adsorption onbiomass waste-derived porous carbons," Science and Technology, vol. 55, pp. 1192511936, 2021.

[31] “Datasets," 2021, https://apps.automeris.io/wpd/.

[32] J. Abdulsalam, A. I. Lawal, R. L. Setsepu, M. Onifade, and S. Bada, "Application of gene expression programming, artificial neural network and multilinear regression in predicting hydrochar physicochemical properties," Bioresources and Bioprocessing, vol. 7, no. 1, pp. 1-22, 2020. 